\title{
STUDI KOMPARASI HASIL BELAJAR MATEMATIKA MENGGUNAKAN MODEL PEMBELAJARAN KOOPERATIF TIPE NUMBERED HEADS TOGETHER (NHT) DAN STUDENT TEAMS ACHIEVEMENT DIVISION (STAD)
}

\author{
Sri Fatoyah ${ }^{1}$, Akhmad Nayazik $^{1}$, Arie Wahyuni ${ }^{1}$ \\ ${ }^{1}$ Universitah Ivet, Jalan Pawiyatan Luhur IV No.17 Bendan Dhuwur, Semarang 50233, Indonesia \\ Email: Sri.fatoyah@gmail.com \\ Email: ahmadnayazik@gmail.com \\ Email: ariewahyuni20@gmail.com
}

\begin{abstract}
Abstrak
Penelitian ini bertujuan untuk mengetahui manakah yang lebih baik antara hasil belajar matematika pada siswa SMP Cokroaminoto Batang yang diajar menggunakan model pembelajaran kooperatif tipe Numbered Head Together (NHT) atau yang diajar menggunakan model pembelajaran kooperatif tipe Student Teams Achievement Division (STAD) pada bidang matematika materi segiempat. Sampel penelitian ini terdiri 2 kelas yaitu kelas eksperimen 1 dan kelas eksperimen 2 dengan menggunakan metode $N H T$ dan STAD. Penelitian ini menggunakan metode penelitian kuantitatif. Metode pengumpulan data yang digunakan adalah metode dokumentasi dan tes. Instrumen penelitian berupa perangkat pembelajaran dan soal tes hasil belajar matematika. Analisis data yang dilakukan adalah uji prasyarat dengan menggunakan uji kesamaan rata-rata dan uji hipotesis dengan menghitung rata-ratanya. Hasil penelitian menunjukkan bahwa rata-rata hasil belajar siswa kelas eksperimen 1 sebesar 76.875 dan kelas eksperimen 2 sebesar 72.56667 yang artinya bahwa hasil belajar kelas yang diajar dengan model pembelajaran kooperatif tipe NHT lebih baik dari hasil belajar kelas yang diajar dengan model pembelajaran kooperatif tipe STAD. Dari hasil penelitian, dapat disimpulkan bahwa model pembelajaran kooperatif tipe NHT lebih efektif jika dibandingkan dengan model pembelajaran kooperatif tipe STAD pada pokok bahasan segiempat pada siswa kelas VII SMP Cokroaminoto Batang Tahun Ajaran 2018 / 2019.
\end{abstract}

Kata kunci: model pembelajaran kooperatif tipe STAD, model pembelajaran kooperatif tipe NHT, hasil belajar.

\begin{abstract}
This study aims to find out which is better between mathematics learning outcomes in Cokroaminoto Batang Junior High School students who are taught using the Cooperative learning model Numbered Head Together (NHT) or those who are taught using the Cooperative learning model type Student Teams Achievement Division (STAD) in the material mathematics field rectangular. The sample of this study consisted of 2 classes, namely experimental class 1 and experimental class 2 using the NHT and STAD methods. This study used qualitative research methods. Data collection methods used are documentation and test methods. Research instruments in the form of learning tools and mathematics test results. Data analysis performed was a prerequisite test using the average similarity test and hypothesis testing by calculating the average. The results showed that the average learning outcomes of experimental class 1 students amounted to 76,875 and experimental class 2 amounted to 72,56667 which means that classroom learning outcomes taught by NHT type cooperative learning models were better than classroom learning outcomes taught by the STAD type cooperative learning models. From the results of the study, it can be concluded that the NHT type of cooperative learning model is more effective when compared to the STAD type cooperative learning model on the subject of quadrilateral in class VII students of Cokroaminoto Batang Middle School Academic Year 2018/2019
\end{abstract}

Keywords: STAD Model, NHT Model, Learning Outcomes 


\section{PENDAHULUAN}

Pembelajaran adalah sekumpulan peristiwa (events) yang mempengaruhi siswa sedemikian rupa sehingga siswa itu memperoleh kemudahan di dalam belajar (Anni, 2009). Pembelajaran matematika merupakan proses aktivitas siswa yang mengkonstruksikan pengetahuan metematika yang memahami hubungan, norma serta simbol yang nyata (Wahyuni, 2017). Berdasarkan pendapat tersebut, proses belajar menjadi sangat penting terutama dalam pembelajaran matematika. Guru harus bisa memberikan pemahaman konsep matematika dengan baik supaya dapat mempermudah dalam proses belajar terutama dalam proses kemampuan pemecahan masalah matematika. Pembelajaran matematika adalah suatu proses yang di dalamnya terkandung kemampuan, potensi, minat, bakat, dan kebutuhan siswa tentang matematika dari (Suyitno, 2004). Berdasarkan kutipan tersebut, ini artinya seorang guru harus dapat membuat suasana pembelajaran yang menyenangkan sehingga memudahkan siswa untuk menangkap materi pelajaran. Menurut Asikin (2001), perkembangan ilmu pengetahuan dan teknologi yang semakin pesat mengakibatkan permasalahan yang dihadapi manusia semakin kompleks, sehingga berbagai model, teknik dan metode pembelajaran dikembangkan agar kemampuan siswa dapat dikembangkan secara maksimal. Walaupun proses perkembangan ini telah dilakukan selama bertahun-tahun, permasalahan yang dihadapi di Indonesia selalu sama, yaitu mata pelajaran matematika masih dianggap sebagai pelajaran yang sulit, menakutkan, dan kurang berguna bagi kehidupan sehari-hari. Pemilihan model pembelajaran yang tepat harus memperhatikan kondisi siswa, sifat materi bahan ajar, fasilitas media yang tersedia, dan kondisi guru itu sendiri.

Proses belajar mengajar di SMP biasanya peran seorang guru masih mendominasi kelas menyebabkan pembelajaran yang berlangsung tidak menyenangkan dan dapat menyebabkan kejenuhan. Keberhasilan pembelajaran di sekolah akan terwujud dari keberhasilan belajar siswa (Siagian, 2015). Untuk mengatasi permasalahan tersebut diperlukan suatu pembelajaran yang tepat dan menarik, dimana siswa dapat belajar secara aktif dan dapat menumbuhkan minat siswa dalam belajar matematika.Untuk menciptakan suasana pembelajaran yang inovatif guru diharapkan mengetahui hakikat matematika, hakikat anak, dan cara mengajarkan matematika yang berdasarkan teori yang ada. Hal tersebut sangat diperlukan bagi guru agar dasar dan tujuan pengajaran menjadi jelas dan efisien. Depdiknas (2007) menyatakan bahwa mata pelajaran matematika bertujuan agar siswa memiliki kemampuan sebagai berikut: (1) memahami konsep matematika, menjelaskan keterkaitan antar konsep dan mengaplikasikan konsep atau algoritma secara luwes, akurat, efisien, dan tepat dalam pemecahan masalah; (2) menggunakan penalaran pada pola dan sifat, melakukan manipulasi matematika dalam membuat generalisasi, menyusun bukti, atau menjelaskan gagasan dalam pernyataan matematika; (3) memecahkan masalah yang meliputi kemampuan memahami masalah, merancang model matematika, menyelesaikan model dan menafsirkan solusi yang diperoleh; (4) mengkomunikasikan gagasan dengan simbol, tabel, diagram, atau media lain untuk memperjelas keadaan atau masalah; dan (5) memiliki sikap menghargai kegunaan matematika dalam kehidupan, yaitu memiliki rasa ingin tahu, perhatian, dan minat dalam mempelajari matematika, serta sikap ulet dan percaya diri dalam pemecahan masalah.

Materi segi empat merupakan salah satu materi pelajaran matematika yang diberikan di SMP kelas VII semester genap. Kenyataannya, dalam mempelajari materi tersebut banyak siswa yang belum atau kurang memahami konsep. Oleh karena itu diperlukan model pembelajaran untuk meningkatkan pemahaman siswa tentang konsep materi ini.Salah satu model pembelajaran yang sesuai dengan tuntutan kurikulum tingkat satuan pendidikan adalah model pembelajaran kooperatif. Pembelajaran kooperatif tidak hanya unggul dalam membantu siswa memahami konsep-konsep yang sulit, tetapi juga sangat berguna untuk menumbuhkan kerjasama, berpikir kritis, kemauan membantu 
teman dan sebagainya. Pembelajaran kooperatif diperoleh beberapa temuan tentang pengelolaan pembelajaran cukup baik (Karuru, 2017). Pembelajaran kooperatif merujuk pada berbagai macam model pengajaran dimana para siswa bekerja dalam kelompok-kelompok kecil untuk saling membantu satu sama lainnya dalam mempelajari materi pelajaran. Dalam kelas kooperatif para siswa diharapkan dapat saling membantu, saling mendiskusikan, dan berargumentasi mengasah pengetahuan yang mereka kuasai saat itu dan menutup kesenjangan dalam pemahaman masingmasing.

Pembelajaran kooperatif mencakup suatu kelompok kecil siswa yang bekerja sebagai sebuah tim untuk menyelesaikan suatu tugas, atau mengerjakan sesuatu untuk mencapai tujuan bersama lainnya. Menurut Nugroho \& Edi (2009) pembejaran kooperatif merupakan model pembelajaran melatih bekerjasama. Menurut Killen (2009) pembelajaran kooperatif adalah strategi mengajar yang paling banyak diteliti, serta menurut Dell (2007) pembelajaran kooperatif adalah pembelajaran yang meyediakan kesempatan. Dari ketiga pendapat tersebut diatas dapat disimpulkan bahwa pembelajaran kooperatif merupakan pembelajaran melatih bekerjasama derngan strategi mengajar yang banyak diteliti dan menyediakan kesempatan.

Dalam menyelasaikan tugas kelompok, setiap anggota saling bekerjasama dan membantu untuk memahami suatu bahan pembelajaran. Slavin (2005) pembelarajaran kooperatif dapat diaplikasikan untuk semua kelas. Pembelajaran kooperatif merupakan suatu model pembelajaran yang mendorong siswa aktif mengkonstruksi pengetahuannya sendiri. Siswa belajar dalam kelompok kecil yang kemampuannya heterogen. Selama kerja kelompok, tugas anggota kelompok adalah mencapai ketuntasan materi dan saling membantu teman sekelompoknya mencapai ketuntasan. Dalam pembelajaran kooperatif terdapat bermacam-macam tipe, diantaranya adalah tipe Numbered Head Together (NHT) dan Student Team Achievement Division (STAD). Farihal (2005) mengungkapkan bahwa penerapan pembelajaran kooperatif tipe STAD, siswa lebih mudah memahami meteri.. Berdasarkan latar belakang tersebut, penulis bermaksud melakukan penelitian tentang manakah yang lebih efektif antara model pembelajaran kooperatif tipe STAD dan tipe NHT ditinjau dari hasil belajar matematika pada materi pokok segiempat kelas VII semester genap SMP Cokroaminoto Batang tahun ajaran 2018/2019.

\section{METODE PENELITIAN}

Penelitian ini merupakan jenis penelitian eksperimen raitu penelitian yang dilakukan untuk mengusahakan timbulnya variabel-variabel, dalam hal ini adalah penerapan metode pembelajaran kooperatif tipe Numbered Head Together (NHT) dan Student Team Achievement Division (STAD) dalam pembelajaran matematika. Sampel penelitian ini melibatkan dua kelas, yaitu kelas eksperimen 1 dan kelas eksperimen 2. Pada kelas eksperimen 1 diberikan pembelajaran menggunakan model pembelajaran kooperatif tipe Numbered Head Together (NHT) dan pada kelas eksperimen 2 diberikan pembelajaran dengan model pembelajaran kooperatif tipe Student Team Achievement Division (STAD).

Penelitian ini dilakukan di SMP Cokroaminoto Batang pada tanggal 25 Maret sd 30 April 2019. Desain penelitian yang digunakan yaitu pretest-posttest. Dalam desain ini terdapat dua kelompok yang kemudian diberi pretest untuk mengetahui keadaan awal. Dalam penelitian ini nilai awal diambil dari nilai semester ganjil. Instrumen untuk mengumpulkan data berupa soal posttest yang dibuat dan dikembangkan sendiri oleh peneliti. Soal-soal ini digunakan untuk mengetahui kemampuan akhir hasil belajar siswa setelah mengikuti proses pembelajaran. Instrumen penelitian ini menggunakan rencana pelaksanaan pembelajaran dan lembar kerja siswa. Teknik analisis data dari penelitian ini menggunakan uji perbedaan rata-rata dimana untuk mengetahui adakah perbedaan hasil belajar siswa menggunakan model NHT dengan menggunakan model STAD. 


\section{HASIL PENELITIAN DAN PEMBAHASAN}

Pengujian hipotesis ini digunakan untuk mengetahui perbedaan hasil pembelajaran antara model pembelajaran kooperatif tipe NHT dan STAD. Uji-t yang dilakukan peneliti menggunakan bantuan program SPSS dengan IndependenT-Tes dengan taraf signifikasi 0,05. Berikut ini adalah uji-t dengan bantuan SPSS

Tabel 1. Hasil Uji Perbedaan Rata-Rata

\section{Group Statistics}

\begin{tabular}{|l|l|l|l|l|l|}
\hline & Kelas & N & Mean & Std. Deviation & $\begin{array}{l}\text { Std. Error } \\
\text { Mean }\end{array}$ \\
\hline \multirow{2}{*}{ hasil belajar } & Kelas NHT & 32 & 76.8750 & 7.92607 & 1.40114 \\
& kelas STAD & 30 & 72.5667 & 6.75014 & 1.23240 \\
\hline
\end{tabular}

Tabel.2. Hasil Uji Perbedaan Rata-Rata

\section{Independent Samples Test}

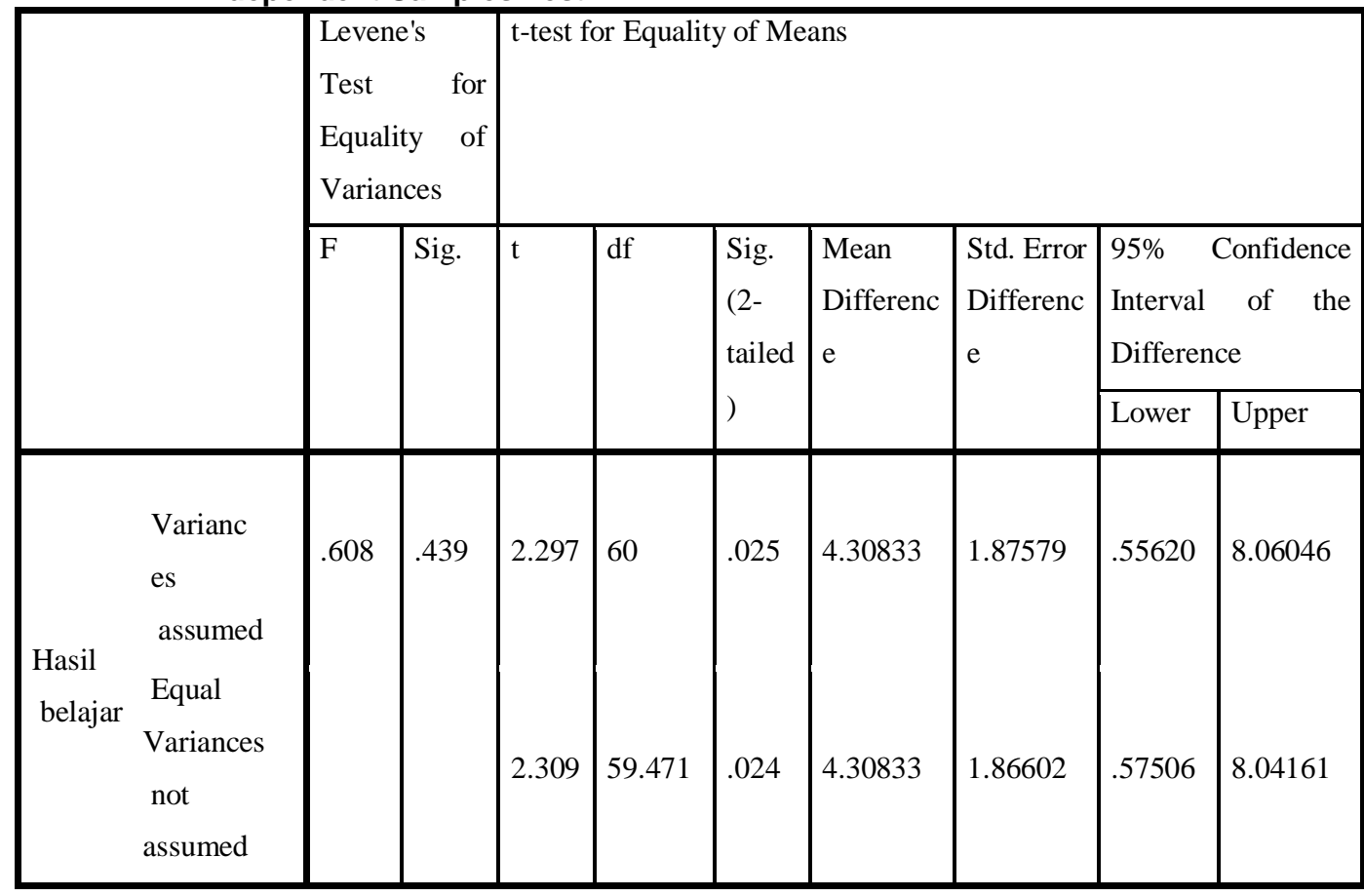

Kesimpulannya tidak ada perbedaan antara model pembelajaran NHT dengan model pembelajaran STAD. Tetapi dengan melihat hasil mean/rata-rata hasil belajar siswa, maka hasil mean model pembelajaran NHT $=76.8750$ sedangkan hasil mean model pembelajaran STAD $=72.5667$. Berdasarkan hasil tes hasil belajar matematika siswa pada kelas eksperimen 1 dan 2, maka dilakukan uji rata-rata tes hasil belajar. Setelah dilakukan uji uji rata-rata tes hasil belajar, dengan rata-rata hasil belajar kelas eksperimen $1=76,875$ dan rata-rata hasil belajar kelas eksperimen $2=72,56667$. Sesuai dengan penelitian Rahmawati (2014) bahwa model NHT dapat meningkatkan keefektifan hasil belajar siswa.

Dari hasil uji kesamaan rata-rata dapat disimpulkan bahwa nilai hasil belajar kelas eksperimen 1 lebih baik dari kelas eksperimen 2. Dan dapt dilihat juga dari hasil belajar kedua kelas, baik kelas 
eksperimen 1 maupun kelas eksperimen 2 sudah memenuhi KKM. Dari kedua hal tersebut dapat disimpulkan bahwa pembelajaran kooperatif tipe NHT lebih efektif meningkatkan hasil belajar matematika dibandingkan pembelajaran kooperatif tipe STAD. Sesuai dengan pendapat dengan penelitian Kusuma at el (2008) model tipe NHT berbasis SAVI dapat meningkatkan hasil belajar kimia siswa, serta penelitian Permana (2016) metode pembelajaran NHT dapat meningkatkan hasil belajar siswa. Terjadinya perbedaan hasil belajar pada kelas eksperimen 1 dan kelas eksperimen 2 karena pada kelas eksperimen 1 siswa lebih dituntut untuk benar-benar memahami materi yang dipelajari. Hal ini dikarenakan pada kelas eksperimen 1, yaitu kelas yang diberi perlakuan dengan pembelajaran kooperatif tipe NHT, semua siswa mempunyai peluang yang sama untuk mempresentasikan hasil diskusi kelompok karena guru langsung menunjuk satu nomor anggota kelompok. Sependapat dengan penelitian Utami (2015) pembelajaran kooperatif STAD mampu meningkatkan hasil belajar. Sehingga semua siswa harus siap jika ditunjuk oleh guru. Sedangkan pada kelas eksperimen 2, guru menunjuk salah satu kelompok untuk mempresentasikan hasil diskusi sehingga masih ada siswa yang hanya mengandalkan jawaban teman sekelompoknya dan melemparkan tanggung jawab kepada teman sekelompoknya yang dianggap mampu atau pandai. Sehingga dapat dikatakan bahwa model pembelajaran Numbered Head Together (NHT) dapat digunakan dalam pembelajaran matematika pada materi persegi panjang, dan persegi. Pembelajaran akan lebih efektif dan efisien, serta lebih menyenangkan dan siswa akan merasa nyaman dalam mengikuti pembelajaran.

\section{KESIMPULAN}

Berdasarkan hasil penelitian dan pembahasan, maka dapat diambil kesimpulan bahwa hasil belajar matematika siswa yang pembelajarannya menggunakan model pembelajaran kooperatif tipe NHT lebih baik dibandingkan dengan hasil belajar matematika siswa yang pembelajarannya menggunakan model pembelajaran kooperatif tipe STAD pada siswa kelas VII SMP Cokroaminoto Batang tahun pelajaran 2018 / 2019.

\section{REFERENCES}

Dell' Olio. J. M., \& Ponk, T. (2007). Model Of Teaching. Thousand Oaks: Sage Publications.

Farihah, L. (2005). Model Pembelajaran Kooperatif Tipe STAD Pada Konsep Perubahan Lingkungan Fisika dan Prosesnya Dalam Upaya Meningkatkan Hasil Belajar Siswa. Skripsi: UNNES.

Karuru, P. (2007). STAD Untuk Pembelajaran IPA Biologi. Universitas Terbuka Online. (http://duniaguru.com)

Killen, R. (2009). Effective Teaching Strategies: Lesson From Research and Practice. Victoria: Cengage Learning.

Kusuma, E., Wijayati, N., \& Wibowo, L. S. (2008), Pembelajaran Kooperatif Tipe NHT Berbasis SAVI Untuk Meningkatkan Hasil Belajar Kimia Pada Bahasan Laju Reaksi. Jurnal Inovasi Pendidikan Kimia, 2(1).

Nugroho, U., \& Edi, S. S. (2009). Penerapan Pembelajaran Kooperatif Tipe NHT Berorientasi Ketrampilan Proses. Jurnal Pendidikan Fisika Indonesia, 5(2).

Pernama, E. P. (2016). Penerapan Metode Pembelajaran Melalui Pembelajaran Kooperatif Numbered Head Together (NHT) Untuk Meningkatkan Hasil Belajar dan Berfikir Kreatif Siswa Pada Mata Pelajaran IPS SD. Jurnal Pendidikan Dasar Nusantara. 1(2). 
Rahmawati, D., Nugroho, S. E., \& Putra, N. M. D. (2014). Penerapan Model Pembelajaran Kooperatif Tipe Numbered Head Together Berbasis Eksperimen Untuk Meningkatkan Ketrampilan Proses Sains Siswa SMP. UPEJ Unnes Physics Education Journal, 3(1).

Siagan, R. E. F. (2015). Pengaruh Minat dan Kebiasaan Belajar Siswa Terhadap Prestasi Belajar Matematika. Formatif: Jornal Ilmiah Pendidika, MIPA. 2(2).

Slavin. (2005). Cooperative Learning (Terjemahan Nerulita Kusron). London: Allyn and Bacon.

Utami. S. (2015). Peningktan Hasil Belajar Melaluai Pembelajaran Kooperatif Tipe STAD Pada Permbelajaran Dasar Sinyal Video . Jurnal Perndidikan Teknologi dan Keguruan, 22(4), 424431. 